\title{
Dermoscopy of a Non-Pigmented Eccrine Poroma
}

\author{
Senhaji G ${ }^{1 *}$, El Jouari I ${ }^{1}$, Gallouj $\mathrm{S}^{1}$, Rimani $\mathrm{M}^{2}$ and Mernissi FZ ${ }^{1}$ \\ ${ }^{1}$ Department of Dermatology, University Hospital Hassan II, Fez, Morocco \\ ${ }^{2}$ Hassan Center of Anatomopathology, Morocco
}

*Corresponding author: Ghita Senhaji, Department of Dermatology, University Hospital Hassan II, Fez, Morocco, Tel: +212 600075857; Email: ghitasenhaji1988@gmail.com

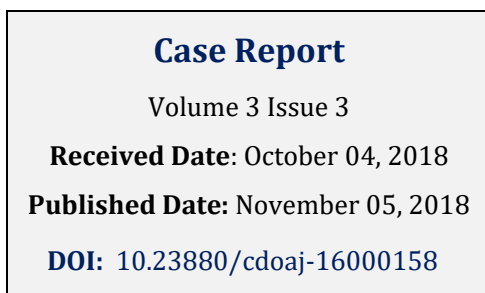

\section{Abstract}

Eccrine poroma, first described by Goldman and Pinkus in 1956, is a rare benign tumor of the intraepidermal portion of the eccrine sweat duct. It represents $10 \%$ of all sweat gland tumors, and only $0.0058 \%$ of epithelial skin tumors. However, it can progress to its malignant counterpart, the porocarcinoma. It commonly occurs on soles and palms, but can also be found on other anatomic sites. As a result of its morphologic variability, it is usually difficult to recognize clinically. Hence the utility of using dermoscopy to guide the diagnosis and eliminate other differential diagnosis. We present a case report of a 54 year old male patient presenting a non-pigmented eccrine poroma of the heel, which we noticed while he was hospitalized for a management of rheumatoid purpura. Through our case, we present a detailed review of clinical and dermoscopical features of this rare tumor along with its histopathological caracteristics, with special interest to dermoscopy.

Keywords: Eccrineporoma; Porocarcinoma; Dermoscopy; Sweat gland tumor; Vascular pattern

\section{Introduction}

Eccrineporoma (EP) is described as an adnexal neoplasm originating from the intraepidermal part of sweat eccrine gland duct, called the acrosyringium [1]. It is a rare benign tumour with variable clinical presentation, thus, the definitive diagnosis is histopathological [2]. However, it can progress to its malignant counterpart, the porocarcinoma [3]. This unusual tumor usually affects bare skin areas [1], mainly the palmoplantar skin [3]. As a result of its morphologic variability, it is usually difficult to recognize clinically [4]. Hence the utility of using dermoscopy to guide the diagnosis. In fact, more than one dermoscopic patterns have been described to characterize this disorder [4]. We describe a case of a 54 year-old male patient presenting with an eccrineporomain the heel discovered fortuitly while he was hospitalized for a management of a rheumatoid purpura, with special attention to its clinical and dermoscopic features.

\section{Case report}

A 54-year-old male patient with a history of a treated pulmonary tuberculosis 13 years ago, was admitted in our Dermatology department for the management of a rheumatoid purpura. He presented with a history of a gradually increasing erythematous nodule of the right heel for 6 months, which was painless and nonpruriginous. There was no history of trauma or infection. 


\section{Clinical Dermatology Open Access Journal}

Clinical examination showed a solitary well-defined firm nodule, of about $1.5 \mathrm{~cm}$, with purplish erythematous color and non-infiltrated base on the right heel, surmounted by thick yellowish scales. Dermoscopy was performed and revealed the presence of a vascular pattern made of homogeneous lacunas resembling those of angioma, with some glomerular vessels by places. The all was surrounded by white to pink halos. With an impression of an amelanotic melanoma or a squamous cell carcinoma, we performed a cutaneous biopsy of the lesion. Histopathological examination showed the presence of a proliferation at the dermoepidermal interface extending into the dermis as large masses made of the anastomosis of bands of basaloid epithelial cells. Small ducts, sometimes dilated, were found within the aggregation of tumor cells along with an abundant fibrous stroma. The diagnostic of an irritated eccrineporoma was made and surgical excision was proposed to the patient. However, he refused the excision and opted for a conservative treatment. Thus, given the benign nature of this tumor, regular clinical and dermoscopic monitoring was performed for 2 years, and showed a steady state without increasing of its size or appearance of signs of malignancy.

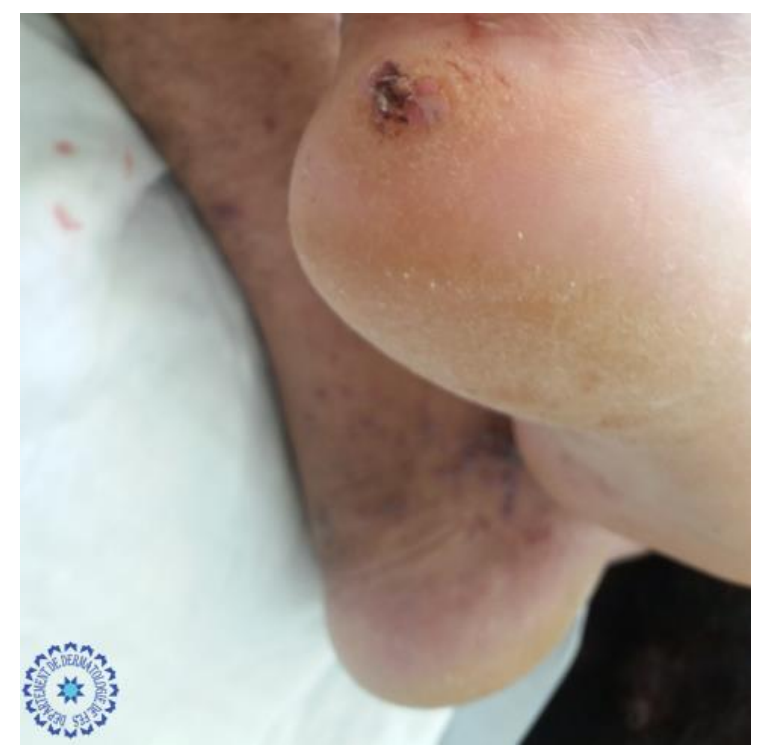

Figure 1: A purple erythematous colored solitary nodule, of about $1.5 \mathrm{~cm}$ in size, without infiltrated base on the right heel, surmounted by thick yellowish scales on the surface.

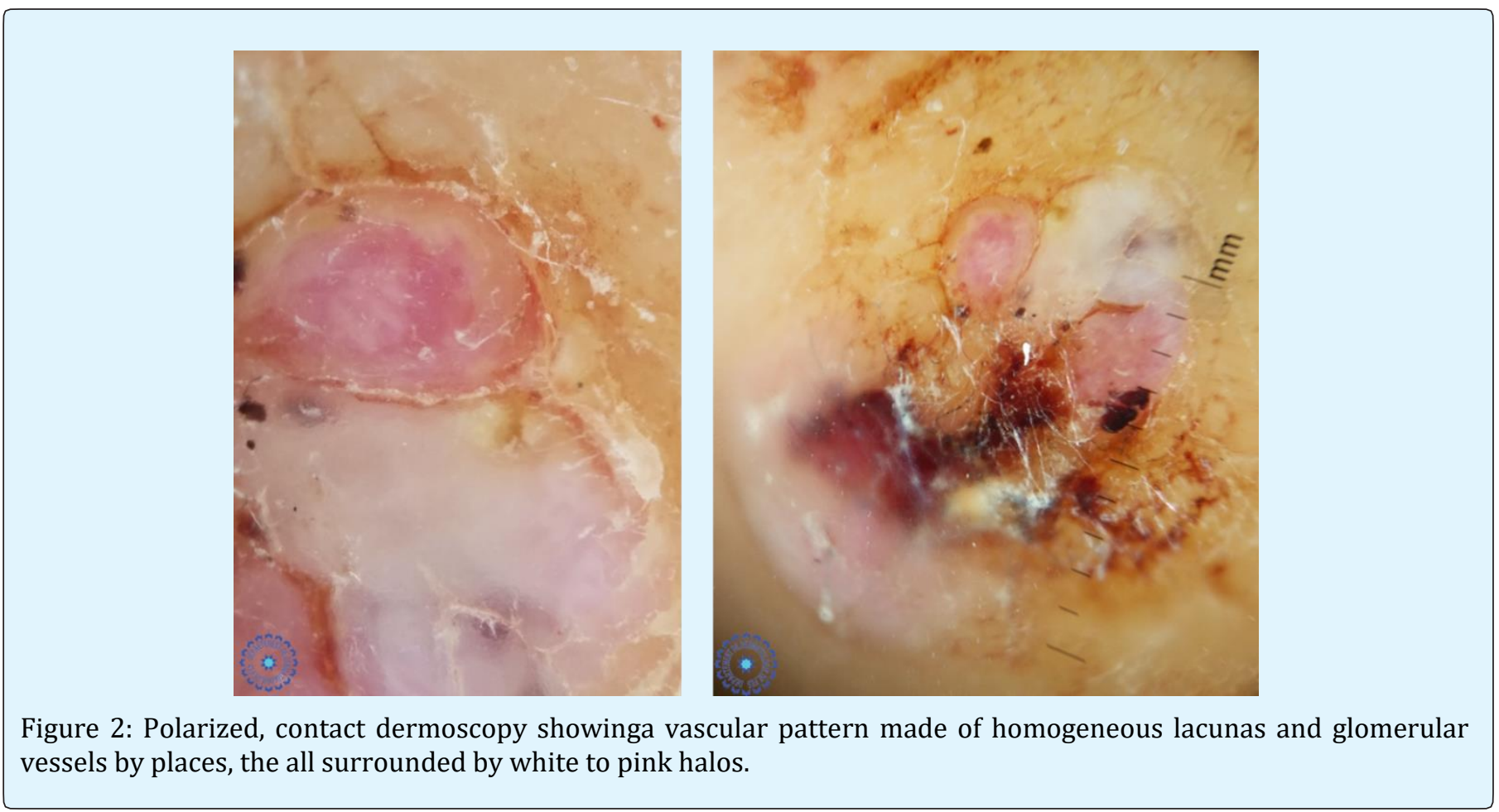




\section{Clinical Dermatology Open Access Journal}
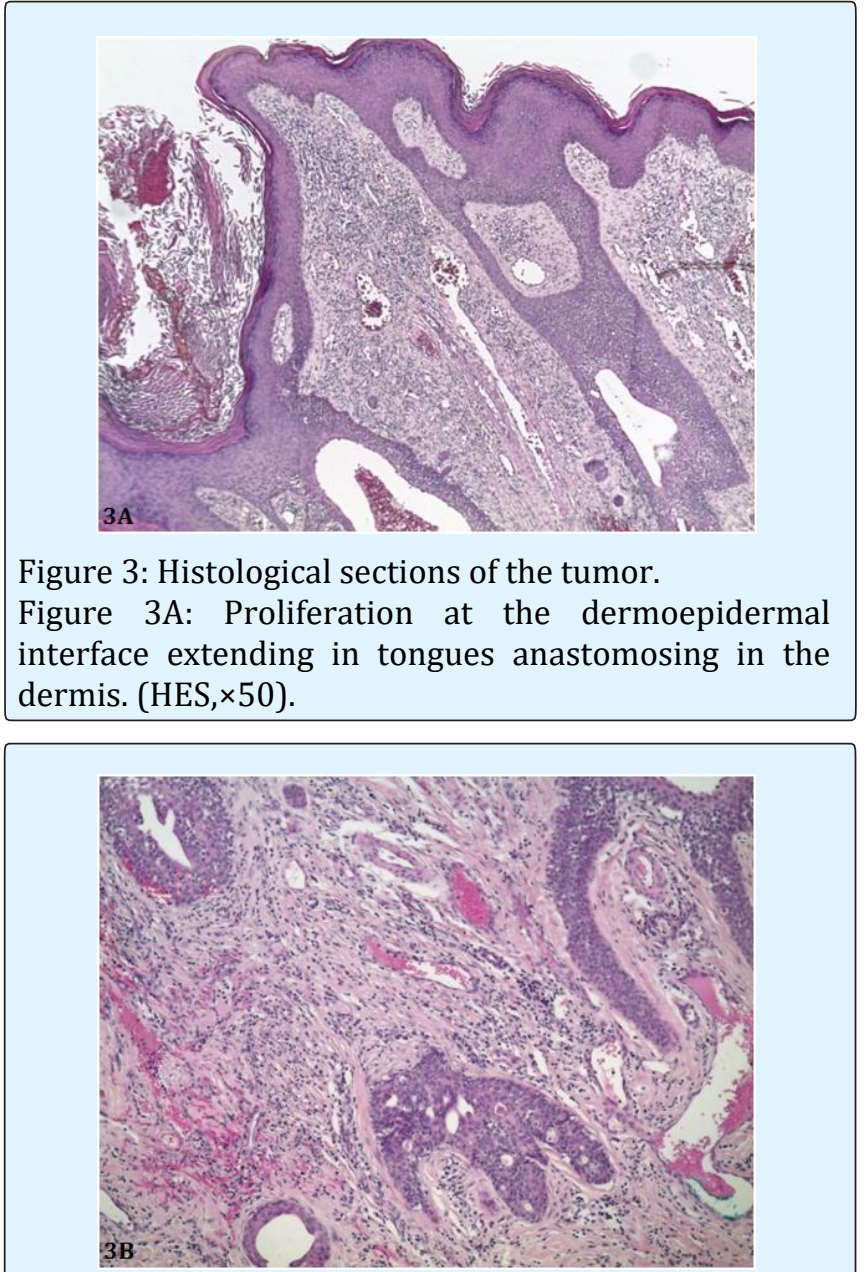

Figure 3B: Basaloid cell proliferation with some ductules in an abundant fibrous stroma richly vascularized and dotted with lymphocytes and plasma cells. $(\mathrm{HES} \times 100)$.

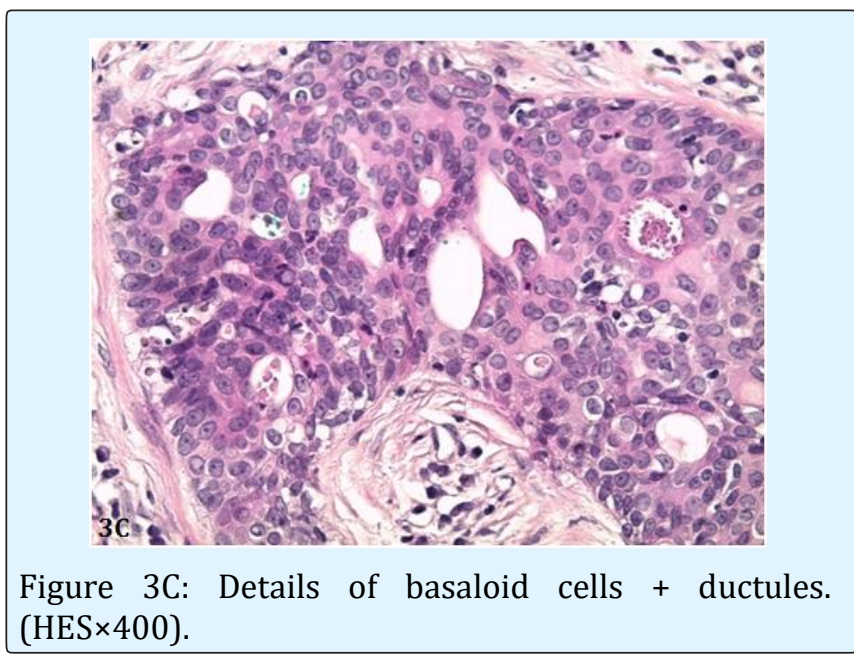

\section{Discussion}

Eccrineporoma, first described by Goldman and Pinkus in 1956, is a rare benign tumor of the intraepidermal portion of the eccrine sweat duct [5]. It represents $10 \%$ of all sweat gland tumors, and only $0.0058 \%$ of epithelial skin tumors [3]. It commonly occurs on soles and palms, but can also be found on other anatomic sites [6]. On the other hand, eccrin eporocarcinomas do exist and they are supposed to originate by malignant transformation of a poroma; however, only $18 \%$ of poromas will actually progress to porocarcinomas [3].

Clinically, EP presents in a mean age of 65 years and with a male predominance, as a single asymptomatic reddish lesion with slow evolution [3]. It appears mostly as moist, exophytic bright red to flesh colored, painful, sessile or pedunculated papule or nodule usually occurring on palms or soles [7]. However, it has been reported to occur at other sites such as scalp, face, neck, chest, abdomen and pubic area [5]. Usually it is a solitary tumor. When multiple lesions appear, the condition is called eccrineporomatosis [6]. Occasionally it can be pigmented and resembles basal cell carcinoma clinically and dermatoscopically [7], or show a distinctive cupshaped depression from which the tumor protrudes and grows [6].

This rare tumor may exhibit polymorphic features that can make the diagnosis difficult [8]. Differential diagnosis described in previous case reports includes a wide range of benign and malignant lesions, such as pyogenic granuloma, hemangioma, seborrheic keratosis, wart, melanocytic nevus, Kaposi sarcoma, cysts, and basal and squamous cell carcinoma [3,5,8]. Moreover, it can mimic malignant tumors, including amelanotic melanoma, which emphasizes the importance of characterizing the dermoscopic patterns of non-melanocytic lesions [6].

In fact, dermoscopic findings of non-pigmented EP have been scarcely reported [2], however, it is characterized by a vascular pattern, which may be polymorphous [9]. It might perfectly mimic most of the common benign and malignant tumours and, therefore, merits to be characterized as a great dermoscopic imitator [4]. Glomerular, hairpin vessels and linear irregular vessels, surrounded by a white to pink halo, may be observed [9]. Furthermore, perivascular whitish halos, which represent a sign of keratinization, have also been observed in several EP, as well as vascular structures resembling the characteristic lacunas of angioma, as in 


\section{Clinical Dermatology Open Access Journal}

our case [4]. However, a unique vascular pattern (flower/leaf-like vessels) was recently described by Aydingoz, and was later found in $42 \%$ of EP in the larger series published $[2,4]$. This vascular pattern seem to combine hairpin and branched vessels [6], and has not yet been described in other cutaneous tumours [2]. Therefore, the presence of this pattern could be a helpful clue in differentiating EP from other benign or malignant non-pigmented neoplasms [6], and thus it helps improve dermoscopic accuracy and avoid unnecessary excisions [2].

Histopathologically, EP arises within the lower portion of the epidermis and it extends downward into the dermis as tumor masses that often consist of broad anastomosing bands of epithelial cells [7]. The tumor is composed of cuticular and poroid cells with a sharp line of demarcation between tumor cells and normal epidermis [5]. These tumor cells are uniformly cuboidal with a round basophilic nucleus, and are connected by intercellular bridges [8]. They have abundant glycogen that gives the cytoplasm a pale appearance [5]. In the majority of cases, small ducts and occasionally cystic spaces are found within the aggregations of tumor cells [6]. Additionally, poromas characteristically show foci of coagulation necrosis, unlike other benign tumors, which is in contrast to the general rule that necrosis en masse points towards malignancy [5].

Poroma's should be differentiated histologically from other benign and malignant lesions, like basal cell carcinoma, trichoepithelioma, eccrineporocarcinoma, hidradenoma papilliferum, and follicular "inclusion" cysts [3].

In addition, enzyme histochemical staining shows prevalence of eccrine enzymes such as phosphorylase and succinate dehydrogenase [8]. By contrast, poromas are Ber-Ep4 negative helping to exclude basal cell carcinoma [3]. Moreover, genetic studies reveal p53 protein expression in eccrineporoma [8].

The etiology of the condition is unknown though trauma, scarring, radiation and viral infection, especially with human papilloma virus are proposed etiological factors [5]. However, it rarely become malignant [5]. Eccrineporocarcinoma, the malignant variant, is more common in elderly patients with more than $50 \%$ of cases occurring in the lower limb, and is characterized by rapid growth up to $10 \mathrm{~cm}$, bleeding, ulceration, itching and pain [7].
Poromas, being benign adnexal neoplasms, treatment is optional [8]. The tumor may be treated by electrosurgery, carbon dioxide laser- assisted removal or by simple excision [5]. Moreover, topical treatments such as $1 \%$ atropine solution have been reported to be beneficial in treatment of superficial lesions [8].

\section{Conclusion}

Through our case, we present a detailed review of clinical and dermoscopical features of this rare tumor along with its histopathological characteristics. Effectively, this tumor may exhibit polymorphic clinical features that can make diagnosis difficult. Hence, it requires the use of non-invasive tools like dermoscopy to help orientate the diagnosis and roll out other malignant tumors.

\section{References}

1. Kong TH, Ha TH, Eom MS, Park SY (2014) Eccrine Poroma of the Auricle: A Case Report. Korean J Audiol 18(3): 151-152.

2. Teixeira AI, Coelho R (2016) sQuiz your knowledge: Erythematous nodule on the leg (Use your dermoscope). Eur J Dermatol 26(5): 519520.

3. Karpathiou G, Mobarki M, Corsini T, Douchet C, Chauleur C, Peoc'h M (2017) Eccrine Poroma of the Vulva. Am J Dermatopathol.

4. Lallas A, Chellini PR, Guimarães MG, Cordeiro N, Apalla Z, et al. (2016) Eccrineporoma: the great dermoscopic imitator. J Eur Acad Dermatol Venereol 30(10): e61-e63.

5. Bhushan P, Thatte SS, Singh A (2015) A fleshy protuberant growth on the leg. Diagnosis: Eccrine poroma. Indian J Dermatol Venereol Leprol 81(6): 652-653.

6. Espinosa AE, Ortega $\mathrm{BC}$, Venegas RQ, Ramírez RG (2013) Dermoscopy of non-pigmented eccrineporomas: study of Mexican cases. Dermatol Pract Concept 3(1): 25-28.

7. Wankhade V, Singh R, Sadhwani V, Kodate P (2015) Eccrineporoma. Indian Dermatol Online J 6(4): 304305. 


\section{Clinical Dermatology Open Access Journal}

8. Mahajan RS, Parikh AA, Chhajlani NP, Bilimoria FE 2014) Eccrine Poroma on the Face: An Atypical Presentation. Indian J Dermatol 59(1): 88-90.
9. Dos Santos BS (2015) Clinical and dermoscopic features of eccrineporoma. Indian J Dermatol Venereol Leprol 81(3): 308-309.

\section{(c) (1)}

